\title{
Sugey López y la pasión por el arte
}

Recibido: 06.07.2020/Aprobado: 15.07.2020

Por Ricardo Morales Velásquez'

En el año 2014 llega a la Escuela de Artes Plásticas la joven Sugey López, a las clases sabatinas, desde las primeras sesiones fue demostrando habilidades excelentes de dibujo, aptitud que me llamó la atención, iniciando una amistad que hasta hoy en día conservamos.

Su permanencia en la Escuela fue poca, porque su tiempo no obedecía a ser una alumna regular, es ahí que me pide llegar a mi taller a recibir orientaciones técnicas relacionadas al dibujo, la pintura y conceptos universales de las artes plásticas.

\section{La perseverancia de Sugey López}

Se hace camino al andar... y es lo que Sugey hace a diario, investigar, experimentar y documentarse para lograr su búsqueda y lo está haciendo muy bien, logrando lo fundamental, es decir, la calidad de ejecución, la fluidez y seguridad de sus manchas y la selección cromática para sus obras que contribuye a la expresividad y al equilibrio compositivo.

Su obra impactante, su característica, el manejo de sus luces, pareciera que tuviera en sus manos una varita mágica que va encendiendo luces en lo que toca. Es admirable como este enjambre de efectos luminosos produzca una sensación de mucha energía en su obra.

Sobre su contenido, dice Sugey: "... si existe un determinado contenido es porque está en mí, aflora.... lo que pasa es que si en mi pintura hay alegría es porque existe en mí, si hay tristeza y soledad, lo mismo", quiere decir que depende de su estado de ánimo y sus circunstancias como todo verdadero artista.

En estos pocos años ha venido incursionando en diferentes temas, como: bodegones, paisajes, retratos. Para el dominio del oficio técnico esto le ha servido en la evolución en su obra, sus frutas, bailarines de El Güegüense y sus personajes ya no obedecen a un realismo fotográfico, pero se sirve de lo académico para entrar en un mundo onírico de transformaciones para expresar sus inquietudes, sin olvidar que la obra de arte se sostiene en la calidad, la expresión y lo novedoso.

Sugey López en el 2019 -2020, ha logrado reconocimiento y premios por su pintura y ha expuesto en varias Autor: Sugey López exposiciones colectivas. Es una artista naciente, nueva, pero con muchos deseos de superación y potencialidad para llegar a estar entre los mejores artistas de su generación.

Managua, 06 de julio 2020.

1 Ex Director de la Escuela Nacional de Bellas Artes de Nicaragua. Correo: rm240826@gmail.com 